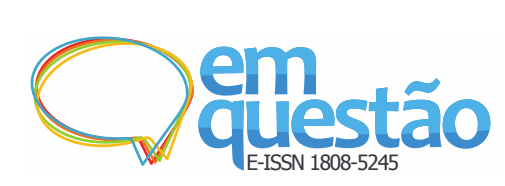

\title{
Dimensões do relacionamento entre a universidade e seus egressos por meio da informação: o caso da Universidade Federal de Minas Gerais
}

\author{
Tatiana Pereira Queiroz \\ Mestra; Universidade Federal de Minas Gerais (UFMG); \\ tattyqueiroz@gmail.com \\ Cláudio Paixão Anastácio de Paula \\ Doutor; Universidade Federal de Minas Gerais (UFMG); \\ claudiopap@hotmail.com
}

Resumo: O propósito deste artigo é apresentar os resultados de um estudo feito para identificar os mecanismos do relacionamento entre uma instituição de Educação Superior e seus egressos. Dessa forma, investigou-se como os sistemas de informação podem ser aperfeiçoados com o objetivo de facilitar a gestão dos dados dos egressos de instituições de ensino com a finalidade de aprimorar a conexão entre eles. O ambiente analisado foi o programa de egressos da Universidade Federal de Minas Gerais, o "Sempre UFMG", e o método de coleta de dados empregado foi o survey eletrônico, cuja amostra apresentou 1.445 respondentes. $\mathrm{O}$ estudo baseou-se nos construtos teóricos sobre identificação social e organizacional, papel, vínculo e necessidade de informação. Os resultados apontam para a indispensabilidade da promoção da relação com o futuro egresso desde o seu ingresso na instituição, mantendo-a ativa ao logo de todo o seu trajeto e continuando após a formação.

Palavras-chave: Usuários de informação. Usuário potencial de informação. Sistemas de informação. Relacionamento com egressos. Identificação organizacional. Vínculo. Tomada de decisão.

\section{Introdução}

Mesmo após todas as mudanças que foram operadas no ensino superior durante os primeiros 15 anos do Século XXI, os egressos das Instituições de Educação Superior (IES) ainda são lançados ao mercado de trabalho para virem a constituir os quadros profissionais do país do mesmo modo que o eram no século anterior. $\mathrm{O}$ afastamento do egresso de sua instituição continua sendo regra, uma vez que o pensamento de que a relação aluno-universidade é interrompida quando este recebe o diploma é praticamente generalizado. A supressão brusca dessa relação, que foi intensa no período discente e que, após a formatura, torna-se quase inexistente, provoca no 
egresso uma sensação de abandono por parte da sua IES. Coelho $\left(2009^{1}\right)$ expõe desta maneira o quadro:

Na maioria dos casos, o diploma representa o corte do cordão umbilical entre a universidade e o egresso e, em conseqüência, desta instituição com a sociedade, pela qual o futuro ex-aluno será envolvido, cheio de expectativas em relação ao mundo do trabalho e ansioso para exercer, em prol da população, a formação recebida.

Contudo, a partir da promulgação da Lei 10.861 de 14/04/2004, que instituiu o Sistema Nacional de Avaliação da Educação Superior (SINAES) (BRASIL, 2004) e, por conseguinte, sua normativa, a Portaria 300 do Ministério da Educação (MEC), de 30/01/2006, que aprovou o instrumento do SINAES de avaliação externa das Instituições de Educação Superior (BRASIL, 2006), esse cenário começou a ser alterado. As IES, que não eram obrigadas a acompanhar os caminhos tomados por seus egressos, passaram a vislumbrar, na manutenção do relacionamento com seus ex-alunos, uma oportunidade de obterem melhor desempenho nas avaliações das instituições de ensino realizadas pelo MEC ao agregarem o acompanhamento desse público ao seu repertório de práticas. Mesmo que forçosamente, as IES, nos últimos anos, começaram, então, a enxergar de modo diferente esse público até então pouco considerado.

Conscientes dessa nova situação, algumas IES estão despertando para o dever de cuidar do grande patrimônio que é o egresso. Criar vínculos vem sendo, ainda que lentamente, reconhecido como um aspecto crucial para a perenidade das instituições que souberem aproveitar a experiência dos egressos para suprir necessidades da própria IES, como, por exemplo, na integração mercadouniversidade, com a participação nas avaliações institucionais e nos demais projetos acadêmicos e extensionistas. No caso das avaliações institucionais, a participação dos ex-alunos torna-se fundamental para a conexão da IES com o mundo do trabalho, à medida que os egressos retornam à universidade com insumos e necessidades do mercado para auxiliar a melhoria dos currículos dos cursos. Segundo Meira e Kurcgant (2009, p. 482):

O egresso enfrenta em seu cotidiano de trabalho situações complexas, que o levam a confrontar as competências desenvolvidas, durante o curso, com as requeridas no exercício profissional. Pode, a partir daí, avaliar a adequação da estrutura pedagógica do curso que foi vivenciado, bem como os aspectos intervenientes no processo de formação acadêmica. 
Diante desse contexto, a questão de o que fazer com o egresso ganha um novo contorno, tornando fundamental que a IES preocupe-se tanto com o caminho percorrido pelo aluno após a conclusão do curso, quanto com o desenvolvimento dos vínculos com esse público. A busca pela excelência, objetivo de toda grande instituição de ensino, aliada à necessidade, cada vez mais premente, da relevância social, torna imprescindível o acompanhamento de egressos, uma vez que estes são o resultado real do aprendizado. De acordo com Lousada e Martins (2005, p. 84), "[...] estabelecer um canal de comunicação com os egressos implica em ouvir aqueles que pela Instituição passaram, cujas percepções, pareceres e críticas possam fundamentar projetos institucionais." Por esse motivo, a necessidade da institucionalização de um programa de ex-alunos para direcionar a política de acompanhamento voltada a eles é salutar para o amadurecimento de uma IES.

Dado o exposto, o objetivo deste trabalho, que apresenta os resultados de uma dissertação (QUEIROZ, 2014), foi o de analisar o relacionamento entre uma IES e seus ex-alunos, no caso, a Universidade Federal de Minas Gerais (UFMG), representada pelo seu programa de egressos, o Sempre UFMG, concebido com a missão de manter os vínculos e a conexão entre ambos. Para tanto, buscou-se compreender como se processa esse relacionamento intermediado pela informação que a Universidade disponibiliza a seus ex-alunos, sendo investigados os interesses informacionais desse público, bem como os fatores de ordem pessoal que promoveriam um relacionamento mais efetivo entre esses ex-alunos e a UFMG.

Utilizando-se dos bancos de dados existentes na UFMG, realizou-se um survey eletrônico que investigou duas frentes: uma voltada para a questão informacional, isto é, as necessidades de informação dos egressos em relação à sua Universidade; e outra direcionada para uma questão interpessoal, de percepção, de registro afetivo e simbólico desse público.

\section{0 programa de egressos da UFMG}

Com 88 anos de existência completados em 2015, a UFMG possui em sua estrutura organizacional três campi universitários, vinte unidades acadêmicas, uma 
administração central e várias unidades especiais, entidades vinculadas e órgãos acadêmicos e administrativos. Teve como primeiro reitor o advogado e professor Francisco Mendes Pimentel, cujo nome seria posteriormente dado à Fundação Universitária Mendes Pimentel (FUMP), instituição de assistência estudantil que, ao longo da história, se mostrou um importante apoio à manutenção estudantil, tendo uma relação bastante próxima com a UFMG.

Em 2000, foi criado o programa Sempre UFMG com o intuito de fazer uma conexão com os egressos da Universidade. Na tentativa de estreitar os laços com esse público, o programa ofereceu aos ex-alunos algumas ferramentas e serviços informacionais na expectativa de atender às suas demandas em relação à informação. Para tanto, era necessário que os egressos atualizassem seus dados, isto é, cadastrarem-se no sistema de informações do Sempre UFMG para terem acesso a esses serviços. No primeiro semestre de 2015, segundo informações do Departamento de Registro e Controle Acadêmico (DRCA) da $\mathrm{UFMG}^{2}$, a Instituição já contava com cerca de 180.000 ex-alunos de graduação e de pós-graduação dos mais diversos cursos. O Quadro 1 apresenta a lista com as atividades e serviços disponibilizados pelo Sempre UFMG a esse público. 
Quadro 1 - Atividades e produtos do programa Sempre UFMG

(continua)

\begin{tabular}{|l|l|}
\hline Atividades/produtos & Descrição \\
\hline $\begin{array}{l}\text { Sistemas de Informações } \\
\text { de Ex-Alunos }\end{array}$ & $\begin{array}{l}\text { Banco de dados no qual são alimentadas informações de contato dos } \\
\text { egressos que atualizam seus dados voluntariamente, por meio de } \\
\text { cadastro na internet. }\end{array}$ \\
Quem é Quem & $\begin{array}{l}\text { Banco de dados de pessoas-chave, composto por ex-alunos da } \\
\text { UFMG que ocupam lugar de destaque nas esferas empresarial, } \\
\text { política, cultural, entidades de classe, etc. }\end{array}$ \\
$\begin{array}{l}\text { Perfil UFMG - Rede de } \\
\text { Oportunidades }\end{array}$ & $\begin{array}{l}\text { Sistema, disponível na internet que oferece ao ex-aluno } \\
\text { possibilidades de inserção no mercado de trabalho e no âmbito da }\end{array}$ \\
Universidade, ao mesmo tempo em que oferece às organizações em \\
geral um cadastro organizado de profissionais formados pela \\
UFMG.
\end{tabular}

Fonte: Elaborado pela autora (Nov. 2013).

\section{Identificação, papel e vínculo do egressos com a sua IES}

Para que seja compreendido o processo de criação dos vínculos entre as IES e seus egressos, é necessário que se apresente o arcabouço teórico que norteou os estudos em questão. Desse modo, considera-se importante apresentar conceitos adotados da Psicologia, como a identificação organizacional, papel e vínculo, assim como conceitos da Ciência da Informação, como necessidade de informação, que fundamentaram a discussão proposta.

A Teoria da Identificação Social de Mael e Ashforth (1992) diz respeito ao sentimento de pertença a um grupo de classificação real ou simbólico (por exemplo: 
"eu sou um homem" e "eu sou um fã do time de futebol local", respectivamente). Através da identificação social, o indivíduo se percebe como psicologicamente entrelaçado com o destino de um grupo, partilhando e experimentando seus sucessos e fracassos (TOLMAN, $1943^{3}$ apud MAEL; ASHFORTH, 1992). Sob esta perspectiva, surge uma forma específica de identificação social em que o indivíduo define a si mesmo, em termos de sua participação em uma organização em particular - a identificação organizacional.

Para que a identificação em instituições de ensino possa acontecer, Mael e Ashforth (1992) sugerem concorrerem pressupostos organizacionais - prestígio e competitividade interinstitucional - e pressupostos individuais - tempo de permanência e de saída da instituição, relação com um mentor, contribuição da IES na consecução dos objetivos pessoais dos alunos e sentimentalismo. Neste contexto, acredita-se que as instituições que conseguirem propiciar um ambiente adequado ao desenvolvimento desses pressupostos, provavelmente, terão alunos mais identificados e, por consequência, contarão no futuro com fiéis defensores e propagadores da marca da IES.

Já McDearmon (2012) aborda a questão do papel do egresso diante da sua instituição de ensino, melhor dizendo, a sua posição/função de egresso perante a sua faculdade ou universidade e que vai, segundo ele, moldar o seu comportamento social, que consequentemente promoverá expectativas no público envolvido. Ele se utiliza da teoria do interacionismo simbólico segundo a perspectiva de Stryker (2002 ${ }^{4}$ apud McDEARMON, 2012). Segundo essa perspectiva, o comportamento humano é dependente de classificações e que estas trazem possibilidades que alimentam o comportamento de uma pessoa e definem uma diretriz para determinar interações sociais de um ambiente. Sendo assim, o interacionismo diz respeito à interação que acontece entre os seres humanos, e consiste no fato de que os homens interpretam as ações uns dos outros ao invés de apenas reagir a essas ações. A resposta de um indivíduo a uma ação de outro é baseada no significado que o primeiro atribui a esta ação (BLUMER, 1986). Ainda de acordo com Stryker (2002 5 apud McDEARMON, 2012) o termo "posição" se refere a qualquer categoria socialmente reconhecida de atores, e o termo "papel" é usado para responder às expectativas que correspondem com a posição em questão. O papel dos alunos ou 
ex-alunos em relação a sua instituição refere-se aos comportamentos dos indivíduos que ocupam essa posição.

Em síntese, as pessoas podem exercer vários papéis ou identidades a partir do momento em que há vontade para tal. Inclusive, em determinados momentos da vida social um papel pode se sobrepor a outro, como é o caso do indivíduo que em idade escolar tem a sua identidade estudantil mais salientada. É esse trecho da teoria que toca a questão do vínculo do egresso com a sua IES e que pode ser promovido ou evidenciado, dependendo da escolha do indivíduo e das expectativas sociais. Entende-se, portanto, a importância do significado que surge dos relacionamentos entre os próprios egressos, e destes com a sua universidade. O papel de um indivíduo enquanto aluno e egresso é ressignificado em todo momento que ocorre uma interação entre as partes e, por conseguinte, pelo processo de interpretação promovida por essa interação.

Faria (2008), partindo da descrição que Bowlby (1969) e Ainsworth (1989) fazem das relações precoces, baseadas nas necessidades de segurança e proteção, que a criança desenvolve com as figuras parentais ou do cuidador, irá transpor essa perspectiva para a criação de vínculos entre adultos. Segundo a autora, "[...] padrões de vinculação desenvolvidos na infância seriam relativamente estáveis ao longo do desenvolvimento e as relações afetivas próximas com os pares seriam o equivalente nos adultos às relações de vinculação na infância." (FARIA, 2008, p. 8). O cenário dessa vinculação para o jovem adulto pode ser assim sintetizado:

\begin{abstract}
$\mathrm{Na}$ sociedade ocidental, a juventude é marcada por acontecimentos normativos como a transição para o ensino superior e o consequente afastamento da família nuclear, o estabelecimento num espaço próprio onde provavelmente pela primeira vez o jovem será responsável por si próprio, o desenvolvimento de relações íntimas com os seus pares, quer de caráter amoroso quer de amizade, o fim da educação formal e início da atividade profissional, e a parentalidade. (CAVANHAUG, $2005^{6} \mathrm{e}$ SCHAIE; WILLIS, $2002^{7}$ apud FARIA, 2008, p. 9).
\end{abstract}

Segundo Hollis (2002), as organizações e as instituições ativam padrões de comportamento que evocam a constituição pessoal das relações dos indivíduos com os pais e a autoridade. Desse modo, assim como a criança que, quando é atingida pela disparidade de poder entre ela e seu pai/mãe/cuidador, faz suas adaptações estratégicas e estabelece seus modelos de relações e vínculos futuros, o indivíduo 
adulto “[...] transfere estratagemas da história para o presente [...]" (HOLLIS, 2002, p. 130). Para o autor, a projeção da autoridade parental para as instituições e suas figuras de liderança cria nos indivíduos a expectativa de que essa instituição será capaz de amá-los, de oferecer segurança e de atendê-los em suas necessidades emocionais.

Desse modo, torna-se muito importante as relações interpessoais adquiridas no período do ensino superior, como a figura do mentor e dos amigos. Esses indivíduos e, no caso específico dos amigos, proporcionam busca de proximidade e fontes de conforto e segurança, caracterizando, assim, uma relação de vinculação, tão relevante na vida adulta (DOHERTY; FEENEY, $2004^{8}$ apud FARIA, 2008).

\section{Necessidade de Informação do egresso}

A questão nuclear desta pesquisa foi a identificação das necessidades informacionais dos usuários e dos usuários em potencial do programa Sempre UFMG. Isto é, se de um lado há os ex-alunos que, ao se inscreverem no referido programa, criam expectativas quanto aos serviços e informações fornecidas por ele, de outro, existem os egressos que não se inscreveram e que, em grande parte, não sabem da existência dele. Neste caso, são os usuários em potencial que fazem parte da grande massa de egressos da Universidade e que podem se tornar usuários reais dos serviços de informação disponibilizados pelo Sempre UFMG.

Dessa forma, há de se identificar a necessidade da informação, o porquê e o como um indivíduo busca a informação que deseja, ou mesmo, deixa de buscá-la porque não sabe que a necessita ou desconhece a sua existência (CRONIN, $1981^{9}$ apud DUMONT, 1994). Como afirmado por Dumont (1994, p. 12), parafraseando Lancaster (1979) ${ }^{10}$, "[...] demandas são bem mais fáceis de serem identificadas do que necessidades, e usuários são bem mais fáceis de serem pesquisados do que não usuários."

Os sistemas de informação são criados para atender às necessidades e às demandas dos usuários, muitas vezes, ainda não identificadas, uma vez que nem sempre os usuários são, de fato, usuários do sistema, mas sim usuários em potencial. A necessidade é o comportamento inicial do processo de busca e uso da informação, 
estando interligada, por vezes, à conscientização de uma lacuna ou deficiência. Tal lacuna ou deficiência pode ser preenchida pela informação ou, em outros casos, por uma necessidade coletiva ou social derivada do contexto. Desse modo, em situações sociais a informação tem que satisfazer a necessidades não só cognitivas, mas também afetivas ou emocionais (WILSON, $1994^{11}$ apud CHOO, 2006).

Le Coadic (2004) ainda classifica a necessidade de informação em dois tipos derivados das necessidades fundamentais. O primeiro, necessidade de informação em função do conhecimento, é derivado do desejo de saber, da pulsão em conhecer. O segundo, necessidade de informação em função da ação, é derivado das necessidades materiais determinadas pela realização das atividades humanas, profissionais e individuais.

Tendo em vista os aspectos observados, entende-se que as necessidades de informação dos usuários ou usuários em potencial devem ser analisadas para determinar a melhoria dos sistemas de informação, que tendem a se interessar apenas por aqueles que o utilizam verdadeiramente, ou seja, os usuários reais (DUMONT, 1994). Desse modo, a análise das necessidades, segundo Le Coadic (2004, p. 43), "[...] é uma atividade interativa que alterna coleta de dados (coleta direta e/ou indireta por meio de medições e levantamentos), análise desses dados e decisão." Também segundo Figueiredo (1994, p. 49), "[...] para planejamento e avaliação de sistemas de informação é requerida uma ampla gama de dados quantitativos, inclusive referentes às necessidades de informação dos usuários."

Nesse contexto, o sistema de informação centraliza os dados que tenham algum significado a um indivíduo ou a uma organização, auxiliando-os no processo geral das atividades (DATE, 2003). Nas IES, a construção destes sistemas que facilitam as atividades de planejamento e gestão dos diversos tipos de assuntos que contornam a administração universitária é fundamental. Figueiredo (1994, p.49) ainda afirma que "[...] os resultados de estudos de usuários podem/devem ser aplicados como diretrizes para o planejamento de novos sistemas de informação e para a avaliação de sistemas já existentes." Percebe-se que para que o relacionamento aconteça entre ambas as partes - egressos e IES -, existe a necessidade de se criar vínculos permanentes, sendo a informação o amálgama para a continuidade dessa relação após a formatura. Desse modo, um sistema de 
informações torna-se um instrumento imprescindível para promover esse relacionamento.

Com essas definições apresentadas, observa-se que a necessidade de informação comunica-se com os referenciais teóricos abordados nas seções anteriores na medida em que ela é pessoal, subjetiva, social e coletiva, e por esse motivo perpassa os aspectos psicológicos de mesma natureza. A identificação, o papel e o vínculo dos ex-alunos enquanto estudantes da UFMG permeiam a questão informacional do início ao fim da passagem destes pela Instituição. Relações de amizade e afinidade, conforme visto na questão do vínculo, podem contribuir para uma maior comunhão de ideias e de interesses (ALCARÁ et al., 2009), facilitando o compartilhamento e a colaboração.

De acordo com esses aspectos, para se entender e aprofundar o entendimento da complexa relação entre uma IES e seus egressos, pode-se sintetizar o que foi apresentado até o momento, refletindo sobre as pesquisas do uso da informação para satisfazer a necessidades não só cognitivas, mas também afetivas ou emocionais (WILSON, 1994; CHOO, 2006); da perspectiva da identificação social (MAEL; ASHFORTH, 1992) sobre a criação de uma identificação com as instituições; de toda a discussão sobre o vínculo entre adultos, como propõe Faria (2008) com base nas teorias de Bowlby (1969) e Ainsworth (1989); da leitura atenta dos trabalhos sobre o deslocamento e a compensação da afetividade oriunda das relações parentais para as instituições, como propõe Hollis (2002); além de outros trabalhos não mencionados diretamente neste artigo, como, por exemplo, sobre a natureza subjetiva da informação, bem como a dependência daquilo que pode ser considerado informativo tem em relação às necessidades interpretativas e às habilidades do indivíduo (CAPURRO; HJORLAND, 2007); a dimensão semântica da informação (NONAKA; TAKEUCHI, 1997); e da formação de pessoas participativas, mediante a ação de mentores/líderes suficientemente bons e capazes de inspirar, emocional e psicologicamente, as pessoas (SAMUELS, 2002).

Por fim, deve-se ressaltar que esta investigação também se orientou pela pesquisa de egressos encomendada pela Diretoria de Avaliação Institucional (DAI) ao Núcleo de Avaliação de Políticas Sociais (NAPS) da Faculdade de Filosofia e Ciências Humanas (FaFiCH) da UFMG (2007), realizada em meados dos anos 2000, 
já motivada pelos preceitos do SINAES. Esta pesquisa teve o intuito de observar o acompanhamento profissional de ex-alunos de 24 cursos de graduação da Universidade formados entre 1980 e 2000 . Além disso, os resultados de um estudo realizado, em 1997, com seis grupos focais de egressos da graduação e pósgraduação da Universidade de Stanford (PEARSON, 1999) também nortearam a investigação em questão. Os grupos eram compostos por recém-formados e exalunos mais antigos que usavam e-mail e Internet à época. Na pesquisa, foram identificadas necessidades informacionais semelhantes em todos os grupos investigados, como:

a) conexão com outros alunos e com a universidade;

b) conhecimento de notícias e informações sobre o que está acontecendo na universidade, pesquisa e bolsas de estudo em curso, programas de associação de ex-alunos e eventos locais;

c) o acesso aos recursos da universidade - bibliotecas, professores e pesquisas de estudante, saúde e recursos médicos;

d) rede de trabalho e carreira;

e) a educação continuada, mais para o enriquecimento pessoal do que para o desenvolvimento profissional.

\section{Delineamento dos procedimentos metodológicos}

Uma vez que o estudo que originou este trabalho se concentrou na manutenção de um contato mais efetivo, ocasionando, possivelmente, um relacionamento entre a Universidade e seus egressos, tornou-se essencial para sua consecução saber quais as necessidades informacionais que os egressos apresentavam em relação ao programa de ex-alunos da UFMG, bem como a relação entre as dimensões identificação social e organizacional, papel e vínculo do egresso e a autopercepção do público participante da pesquisa. Para tanto, foram formuladas três categorias de análise, a saber: perfil demográfico/acadêmico, perfil de identificação/vinculação e perfil de usuário da informação do Sempre UFMG, baseadas no referencial teórico desta pesquisa. 
Como método de coleta de dados, foi proposto um levantamento (survey) exploratório (BABBIE, 1999), via questionário eletrônico autoadministrado, construído em um software de coleta de dados na Internet, o Questionnaire Programming Language (QPL). O questionário contou com 61 questões fechadas e de múltipla escolha, sendo que tais questões objetivaram reconhecer o que o egresso esperava receber de informação da UFMG, bem como suas experiências na Instituição durante a realização do curso e a sua avaliação da UFMG enquanto instituição de ensino superior etc.

Os sujeitos da pesquisa foram os egressos da UFMG tanto da graduação quanto da pós-graduação, cujos contatos de e-mail foram registrados nos bancos de dados do Sempre UFMG e da Universidade, totalizando, à época da pesquisa ( $2^{\circ}$ semestre de 2013), cerca de 40.800 contatos eletrônicos. A título de esclarecimento, ressalta-se que esse número não correspondia ao total de egressos da Instituição, uma vez que os bancos utilizados nesta pesquisa não continham dados de todos os ex-alunos. O sistema do Sempre UFMG é composto por egressos que atualizam seus dados voluntariamente e o sistema da Universidade não realizava de forma sistemática o registro do endereço eletrônico até 2007. Assim, após o término do período destinado à coleta de dados foram contabilizados 1.445 respondentes.

Devido ao caráter exploratório, a amostra foi a não probabilística, utilizandose do critério da confiança em sujeitos disponíveis, que trabalha com os sujeitos acessíveis no momento da aplicação do survey (BABBIE, 1999). Quanto à análise dos dados obtidos pelos questionários, utilizou-se o software livre R para o devido tratamento estatístico das respostas encontradas pelo levantamento, sendo trabalhadas as frequências absolutas e percentuais das variáveis. Ao final das análises, foram desenvolvidos índices de avaliação da UFMG utilizando a análise fatorial exploratória, com finalidade de reduzir a dimensão dos fatores e ter uma visualização da avaliação da UFMG por meio de um número. A Figura 1 sintetiza os procedimentos metodológicos adotados na pesquisa. 
Figura 1 - Resumo dos procedimentos metodológicos

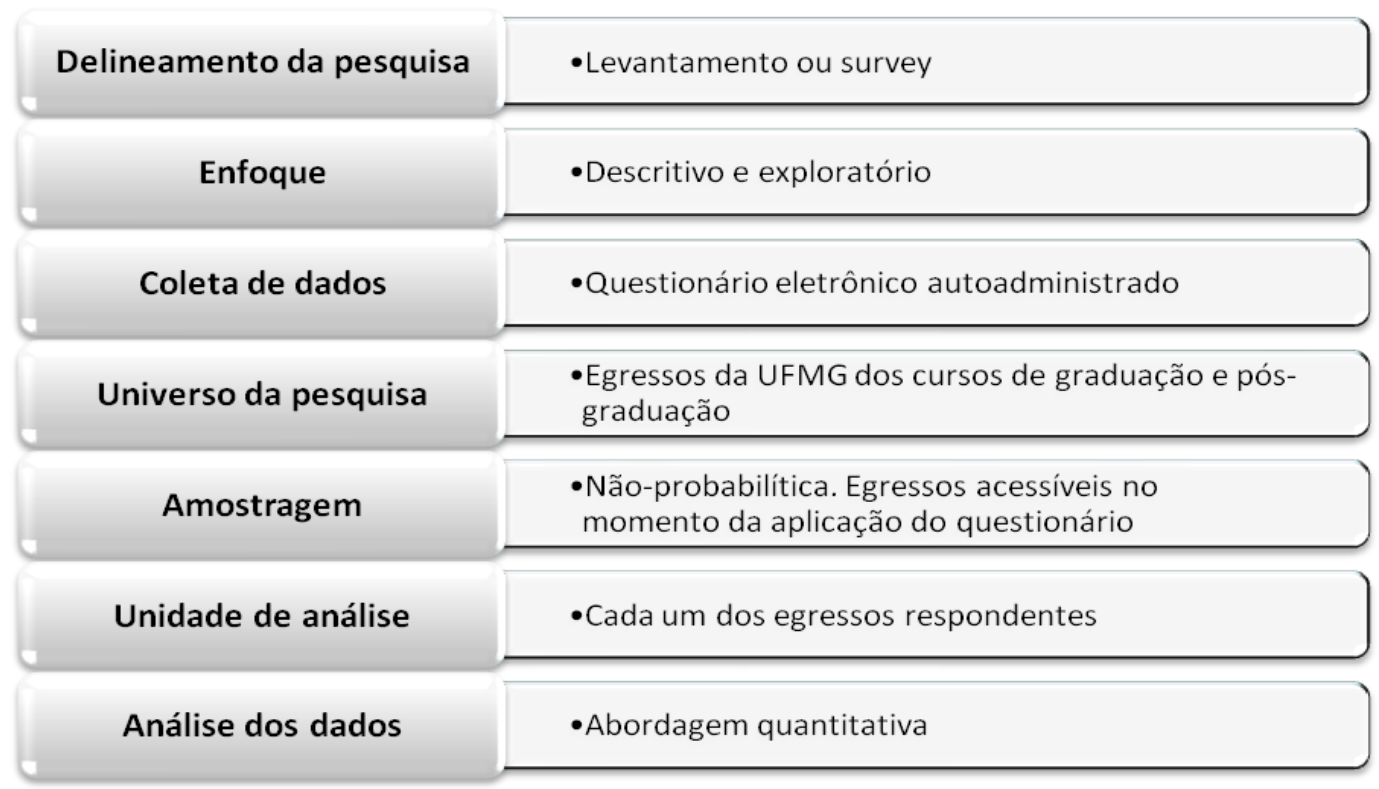

Fonte: Elaborada pela autora (Mar. 2014).

\section{Apresentação dos resultados e discussão}

Em se tratando da identificação demográfica e acadêmica dos egressos, dos 1.445 ex-alunos respondentes da pesquisa, verificou-se que 96\% realizaram apenas um curso de graduação na UFMG e apenas $2 \%$ estão cursando outra graduação atualmente; $55 \%$ eram do sexo feminino; $61 \%$ possuíam idade entre 25 e 39 anos; $45 \%$ eram casados e $45 \%$ solteiros. Com relação à residência anterior ao curso e à residência atual, grande parte dos indivíduos já era residente de Belo Horizonte e assim continuou após a conclusão do curso (60\% e 58\%, respectivamente). A maioria dos respondentes alegou trabalhar na área em que se graduou (73\%), o que para a Instituição é um dado bastante favorável, e 59\% trabalham em organizações públicas.

Quanto à informação sobre em que tipo de instituição o respondente concluiu integralmente ou a maior parte do ensino fundamental e médio, constatou-se a maior porcentagem (57\%) de estudantes oriundos da rede pública no ensino fundamental, sendo essa situação revertida no ensino médio, uma vez que $51 \%$ preferiram a rede privada de ensino. Outra observação importante diz respeito à escolaridade dos pais que, no caso do público respondente desta pesquisa, apresentou 35\% dos pais e $34 \%$ das mães concluintes apenas do ensino fundamental. No entanto, os pais 
apresentaram mais concluintes de nível superior (26\%) que as mães (19\%), que em maior número, concluíram o ensino médio (33\%).

No resultado da pesquisa, constatou-se a marcação de 64 cursos diferentes, contemplando todas as áreas do conhecimento. O curso com o maior número de exalunos participantes foi o de Biblioteconomia, com cerca de $6 \%$ dos respondentes. Não se pode deixar de comentar que tal ocorrência pode ter acontecido pelo fato de esta pesquisa ser oriunda do Programa de Pós-Graduação da Escola de Ciência da Informação da UFMG. Logo, os ex-alunos deste curso podem ter tido mais acesso ao questionário. Sobre o ano de término do primeiro curso de graduação, observouse que $50 \%$ dos respondentes concluíram o primeiro curso na última década, especialmente a partir de 2006. No entanto, deve-se exaltar a participação dos exalunos mais antigos, como aqueles que se formaram nas décadas de 1980 e 1990, que contaram com 14\% e 17\% dos respondentes, respectivamente (Gráfico 1). 
Gráfico 1 - Ano de conclusão do primeiro curso

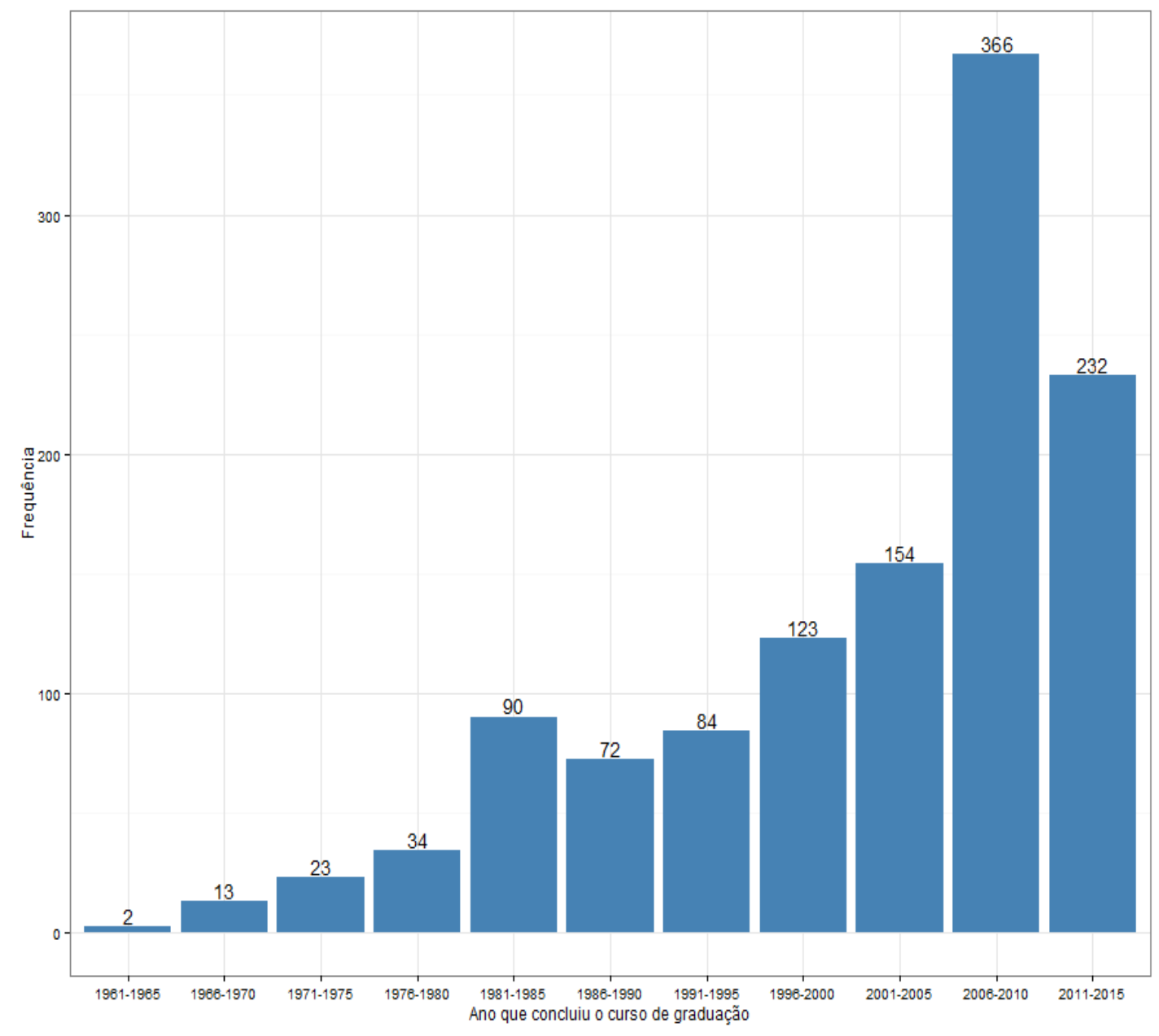

Fonte: Elaborado pela autora (Abr. 2014).

\subsection{Identificação e vinculação do egresso}

No que concerne à identificação e vinculação do egresso, suas opiniões acerca do período discente, observou-se que $64 \%$ dos participantes realizaram alguma atividade de iniciação científica, monitoria ou extensão, porém apenas $34 \%$ receberam apoio da Fundação Universitária Mendes Pimentel (FUMP) de assistência estudantil. A maior parte (69\%) considera a UFMG como sendo uma das cinco melhores universidades públicas do país, o que confirma o fato de $92 \%$ terem avaliado as atividades acadêmicas oferecidas durante o curso como sendo "muito boas" ou "boas". Já as atividades culturais ou de lazer oferecidas pela UFMG não receberam uma marcação tão expressiva $(76 \%)$, como aconteceu no caso das atividades acadêmicas, pois o fato de $21 \%$ terem avaliado essas atividades como 
sendo "ruins" chamou a atenção, indicando a necessidade de mais esforços para incrementar a área cultural na Universidade. Grande parte dos respondentes sempre realizava suas refeições nas instalações da UFMG (52\%) ou, ao menos, algumas vezes (28\%), sendo que $72 \%$ também faziam uso com frequência das bibliotecas, o que mostra a necessidade permanente de investimentos em infraestrutura para suportar essa demanda constante.

De modo geral, a avaliação da UFMG foi muito positiva, já que a maioria expressiva dos respondentes considerou que estudar na Instituição acarretou tanto prestígio social (82\%) quanto prestígio profissional (91\%). Embora a preocupação da UFMG no desenvolvimento profissional do aluno não tenha se mostrado tão contundente para os egressos respondentes, pois a porcentagem que concordou com a questão foi de apenas $36 \%$, mesmo assim, isso não prejudicou a avaliação do prestígio social e profissional. Contudo, evidencia uma desconexão entre mercado e academia, uma vez que esse resultado demonstra que os alunos não sentiram a preocupação efetiva da Instituição quanto ao preparo deles para uma atuação profissional no mercado de trabalho.

Observou-se, também, que a maioria anotou uma avaliação bastante favorável - muito boa ou boa - de questões como estrutura física, 81\%; equipamentos, 67\%; atendimento dos serviços administrativos, 71\%; dedicação e interesse dos professores, 87\%; relação interpessoal com os professores e funcionários administrativos, 93\%; e relação interpessoal com os colegas, 98\%. O Gráfico 2 exibe os itens dessa avaliação.

Gráfico 2 - Avaliação da experiência na UFMG durante o curso 


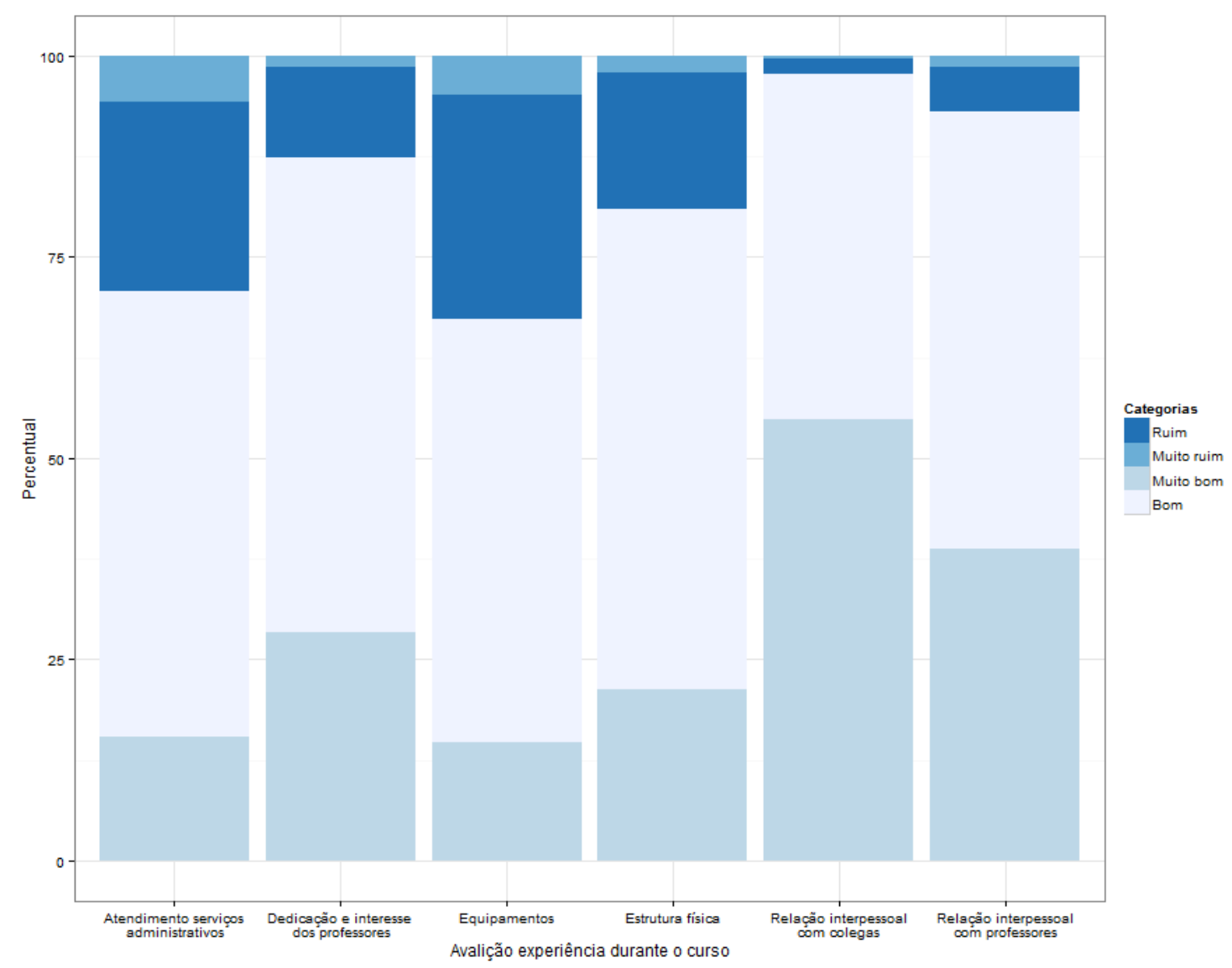

Fonte: Elaborado pela autora (Abr. 2014).

Sobre o recebimento de apoio de um mentor, professor da UFMG, durante o período do curso, $65 \%$ dos respondentes confirmaram este auxílio. Tal ocorrência reitera também o fato de $64 \%$ terem realizado alguma atividade de iniciação científica, monitoria ou extensão, o que, habitualmente, é feito por meio da orientação de um docente.

Ainda no que concerne às questões de percepção do sentimento do ex-aluno em relação à Universidade, $85 \%$ dos respondentes confirmaram que fariam outro curso na Instituição e 98\% recomendariam a UFMG como instituição de ensino a um parente ou amigo. A maioria também afirmou sentir saudades do período de estudante na Universidade (84\%). Os egressos consideraram importante apoiar a UFMG (87\%), entretanto, a criação de um canal para arrecadar contribuições para a Instituição foi apoiada por apenas $45 \%$ dos respondentes e negada por $26 \%$, não demonstrando consenso nesta situação.

No tocante ao modo de contribuir para o desenvolvimento da UFMG, o exaluno respondeu que palestras sobre profissão, carreira ou outros assuntos (63\%); 
trabalho voluntário em projetos sociais promovidos pela UFMG (54\%); e visitas técnicas ou estágios na empresa onde trabalha (45\%) seriam as maneiras mais desejadas para contribuir com a Instituição. Observou-se, de outro lado, que apenas cerca de $20 \%$ dos respondentes gostariam de contribuir com recursos financeiros, o que comprova a divisão das respostas ocorrida na questão sobre a criação de um canal de arrecadação de contribuições para a UFMG - relatada no parágrafo anterior -, em que não houve a aprovação da maioria para a criação de tal canal. Todavia, deve-se ressaltar que apenas $6 \%$ não gostariam de contribuir de alguma maneira, o que demonstra que tal proposição apresenta um apelo favorável à questão, devendo ser considerada pelos gestores da Universidade.

Para concluir esta etapa da pesquisa, os egressos que relataram sentir saudades do período de estudante na UFMG - questão também já mencionada -, selecionaram: ambiente, $85 \%$; colegas, $80 \%$; aulas, $68 \%$; e professores, $60 \%$, como aquilo que eles mais sentiam saudades da Universidade. Estes resultados confirmam as boas relações interpessoais com os colegas e o corpo docente, o que reflete na questão do ambiente e das aulas e, por consequência, na criação dos vínculos. Já as atividades culturais e de lazer e as festas de confraternização foram os itens menos marcados, $37 \%$ e $30 \%$, respectivamente, retratando, talvez, falta de divulgação e de programação cultural e de lazer mais adequada aos anseios dos estudantes.

\subsection{Necessidades de informação dos usuários e dos usuários em potencial do Sempre UFMG}

No que tange à identificação das necessidades dos usuários e dos usuários em potencial do programa Sempre UFMG, observou-se que $76 \%$ tinham conhecimento da existência dele, como era de se esperar, uma vez que os ex-alunos cadastrados no referido programa foram convidados a responder a pesquisa. De outro lado, a maioria expressiva dos respondentes (94\%) também considerava importante a UFMG ter criado o programa de ex-alunos. Este resultado retrate talvez maior sensibilidade dos respondentes com o assunto abordado pela pesquisa, pois quem se dispôs a responder o questionário eletrônico da investigação já demonstrava certa inclinação para a questão em pauta. 
Notou-se, também, que $93 \%$ dos respondentes consideravam interessante estar a par das principais atividades e acontecimentos da UFMG, sendo que $69 \%$ já haviam recebido algum e-mail do Sempre UFMG. Em se tratando do comportamento diante do recebimento de e-mail do referido programa, $71 \%$ o abririam e $27 \%$ o leriam depois. No entanto, apenas 3 respondentes $(0,2 \%)$ teriam a atitude de apagar a mensagem e $2 \%$ consideraram-se indiferentes quanto ao recebimento de e-mail do Sempre UFMG. Conclui-se que, mesmo o público da pesquisa sendo mais atento à questão, o contato com a Universidade ainda se faz importante e desejado.

No que concerne ao conhecimento do banco de oportunidades de trabalho da Universidade, o sistema Perfil UFMG (relatado no Quadro 1), que é um dos serviços já prestados pelo programa, apenas $18 \%$ relataram a ciência de tal sistema. O fato de $75 \%$ terem relatado que não conheciam o Perfil UFMG evidenciou uma falha na divulgação desse produto do Sempre UFMG, uma vez que a maioria dos respondentes afirmou ter conhecimento do programa e, por consequência, deveria também ter conhecimento do banco de oportunidades.

No tocante ao que o ex-aluno considerava que seria mais importante a UFMG promover ou disponibilizar aos seus ex-alunos para manter um vínculo mais próximo, $82 \%$ preferiram desconto nos cursos de especialização e extensão da Universidade, seguindo-se: banco de oportunidades de trabalho direcionado aos exalunos (79\%), empréstimo domiciliar nas bibliotecas (58\%) e envio, via e-mail, de notícias da UFMG (56\%). Uma vez que tanto o banco de oportunidades quanto o envio de notícias já são contemplados nas atividades do Sempre UFMG, os descontos nos cursos de especialização e extensão oferecidos pela Instituição, bem como o empréstimo domiciliar nas bibliotecas deveriam ser opções a serem estudadas com atenção pelos gestores da Universidade.

No que se refere ao contato do egresso com ex-colegas ou ex-professores foi observado que $83 \%$ afirmaram manter o contato por meio de e-mail (66\%), redes sociais $(60 \%)$ e telefone $(44 \%)$. Com relação às informações que seriam relevantes os egressos receberem da UFMG para o desenvolvimento da sua profissão, seminários, palestras e encontros científicos $(86 \%)$ e cursos de pós-graduação $(76 \%)$ 
e de extensão (74\%) foram as alternativas mais selecionadas pelos respondentes, reiterando o interesse na educação continuada por parte do ex-aluno.

Finalizando este estágio do trabalho, o modo como os egressos gostariam de receber as informações da UFMG, o e-mail foi eleito o meio preferencial para $97 \%$. Redes sociais (29\%), cartas (13\%) e mensagens de texto no celular (9\%) também foram outras opções selecionadas. $\mathrm{O}$ fato de nem mesmo $1 \%$ dos respondentes não desejar receber informações da Universidade reforça a vontade do egresso em manter contato. $\mathrm{O}$ resultado obtido com as redes sociais também reitera o fato de este tipo de contato ainda estar se firmando como um importante canal de comunicação entre a UFMG e seus egressos, uma vez que até o momento não ultrapassou o e-mail como principal meio de contato.

\section{3 Índices de avaliação da UFMG pelos ex-alunos}

Para a criação dos índices, utilizou-se a análise fatorial para descrever relações da estrutura de covariância entre algumas variáveis em termos de fatores. Nesta análise foram empregadas variáveis que se referiam às questões de avaliação dos respondentes com respeito a UFMG no período em que realizaram o curso. Essas questões, compostas por oito variáveis, possuíam em comum uma escala ordinal de quatro pontos, cujos valores eram:
a) $1=$ Muito ruim;
b) 2 = Ruim;
c) $3=$ Bom;
d) $4=$ Muito bom.

Foram estimadas as cargas fatoriais para aproximarem as variáveis, cujos resultados proporcionaram a observação de três grupos de variáveis:

a) avaliação da estrutura da UFMG (equipamentos, infraestrutura física e serviços administrativos): índice 1 (três variáveis);

b) avaliação da dedicação e do interesse dos professores e da relação interpessoal com professores, funcionários administrativos e colegas: índice 2 (três variáveis); 
c) avaliação das atividades acadêmicas e culturais ou de lazer: índice 3 (duas variáveis).

A construção desses três índices com base no resultado da análise fatorial se deu da seguinte forma:

a) avaliação da consistência interna das variáveis dentro de cada grupo de variáveis por meio do coeficiente alpha de Cronbach;

b) valores de alpha iguais ou superiores a 0,65 indicam boa consistência. Assim as variáveis do mesmo grupo foram somadas, constituindo um índice.

Os dois primeiros grupos de variáveis apresentaram boa consistência (avaliação da estrutura da UFMG - alpha $=0,73$; avaliação da dedicação e relação interpessoal - alpha $=0,65)$, enquanto que o último grupo de variáveis apresentou uma consistência próxima da aceitável (avaliação das atividades acadêmicas e culturais - alpha $=0,55$ ). Os índices foram criados somando-se os valores (de 1 a 4 pontos) das respostas de cada respondente.

Dessa forma, os índices 1 e 2 variam de 3 pontos (respondente que marcou "Muito ruim" nas três questões) até 12 (respondente que marcou "Muito bom" nas três questões), e o índice 3 varia de 2 pontos (respondente que marcou "Muito ruim" nas duas questões) a 8 (respondente que marcou "Muito bom" nas duas questões). Valores baixos para cada índice indicam avaliação ruim, enquanto que valores altos indicam boa avaliação. Na Tabela 1, apresentam-se as estatísticas descritivas dos três índices.

Tabela 1 - Índices referentes à avaliação de estrutura, dedicação dos professores, relação interpessoal e atividades acadêmicas e culturais

\begin{tabular}{lccccc}
\hline & Mínimo & $1^{\mathbf{0}}$ quartil & Mediana & $3^{\circ}$ quartil & Máximo \\
\hline Índice 1 & 3 & 8 & 9 & 10 & 12 \\
Índice 2 & 5 & 9 & 10 & 11 & 12 \\
Índice 3 & 2 & 6 & 6 & 7 & 8 \\
\hline \multicolumn{5}{c}{ Fonte: Elaborada pela autora (Abr. 2014). }
\end{tabular}


A estrutura da UFMG recebeu nota 8 de pelo menos $75 \%$ dos participantes ( $1^{\circ}$ quartil). Dedicação dos professores e relação interpessoal com colegas e professores receberam avaliação ainda melhor, ou seja, nota 9 de pelo menos $75 \%$ dos participantes. Atividades acadêmicas, culturais e de lazer foram avaliadas com nota 6 de ao menos $75 \%$ dos participantes. Os índices encontrados, que representam a soma das respostas dos egressos em três questões específicas - conforme relatado no início desta seção - reiteram a avaliação positiva da UFMG pelos seus ex-alunos.

\section{Considerações finais}

Os resultados desta pesquisa indicam que os egressos procuram, no seu contato com a Universidade, mais que informações pragmaticamente úteis para solucionar seus problemas cotidianos. Eles parecem buscar informações que atendam às suas necessidades psicológicas de construir uma representação de si mesmos na interação com a comunidade de onde saíram, reafirmando suas identidades e utilizando-as como ferramenta na sua interação com a sociedade.

Em decorrência dessa situação, o fato apontado pelo referencial teórico, dos egressos agirem em relação às instituições de onde se originaram com base no significado que eles atribuem a elas, ganha um novo contorno. Se esse significado é derivado de, ou é anterior à interação social que uns têm com outros e com a instituição enquanto um organismo, e que esses significados são controlados ou modificados através de um processo interpretativo usado pelas pessoas em suas interações e nestas com as possibilidades descortinadas pelo seu ambiente, revela-se então uma oportunidade de incrementar a relação do egresso: investir em estratégias de valorização de informações que reforcem o vínculo afetivo com a instituição.

Esse reforço do vínculo afetivo se apresentaria como uma ponte para a identificação com a instituição. Essa identificação, atendendo aos anseios psicológicos dos egressos, quando percebida como elemento constituinte de sua identidade pessoal, profissional e social e, portanto, veículo para sua inserção na sociedade representaria um pré-requisito para o estabelecimento do vínculo formal desejado com a instituição. A construção de tal vínculo, no entanto, deveria ser estimulada, por meio de experiências positivas e construtivas, ainda durante o 
período de realização do curso, isto é, durante todo o ciclo de vida do aluno dentro da instituição, continuando após a formação.

Partindo da premissa de que relacionamento se traduz em trocas recíprocas, gerando benefícios para as partes envolvidas, é desejado que a instituição de ensino transforme essas demandas em serviços informacionais a serem disponibilizados aos egressos, que, por sua vez, sentir-se-ão mais sensibilizados em também atender às demandas da sua Universidade. De modo geral, relacionamento com ex-alunos requer uma mudança na cultura da IES e tem relação direta com o acompanhamento de egressos e com os resultados da formação promovida pelas instituições. É por meio desse acompanhamento que será possível aferir com mais eficácia o desempenho das IES como um todo e colaborar no alcance dos seus objetivos institucionais.

Ademais, os resultados obtidos nesta pesquisa proporcionam conclusões bastante importantes no que tange à tomada de decisão gerencial e permitem a construção de planejamento mais assertivo das ações estratégicas e táticas a serem formuladas, tanto na esfera acadêmica quanto na esfera administrativa das instituições de modo a promover de fato uma conexão com o egresso e, por consequência, o seu acompanhamento após a formação.

Ainda no plano teórico, este artigo faz a junção de duas áreas afins, a Ciência da Informação e a Psicologia, que dialogam neste caso para justificar e compreender as ações propostas aos egressos de uma IES. Os estudos do interacionismo simbólico permitem que se entenda o significado atribuído à informação como decorrente de uma ação interpretativa relacionada com as expectativas dos indivíduos envolvidos em um processo de interação sustentado pela ressignificação dos papéis de aluno e de egresso. Devem ser criadas condições para que o ex-aluno possa interpretar de uma forma ativa no presente o fato de ter sido estudante de uma IES no passado. Este, hoje no lugar de egresso, não deve se sentir como um "ex" e sim como um "sempre" aluno. Nesse sentido, o conceito de informação possibilita conectar as teorias de necessidade de informação e do interacionismo simbólico na medida em que a informação é buscada não para preencher uma lacuna cognitiva, mas para estabelecer uma relação, criar um significado, um sentimento de pertencimento a um grupo e a uma instituição. 
Para finalizar, este estudo oferece contribuições para o desenvolvimento de uma literatura ainda pouco desenvolvida no Brasil sobre a relação entre egressos e suas instituições de ensino superior. Espera-se que este diagnóstico, além de possibilitar à gerência do programa de ex-alunos da UFMG mais conteúdo para reforçar uma tomada de decisão mais assertiva do ponto de vista informacional e, assim, reformular o seu sistema de informações de modo a atender com mais eficiência este público, também auxilie os programas de egressos já existentes ou ainda em formulação de outras instituições a obter referencial auxiliar a ser utilizado no planejamento de suas atividades.

\section{Referências}

AINSWORTH, Mary. Attachments beyond infancy. American Psychologist, v. 44, n. 4, 709-716, 1989.

ALCARÁ, Adriana R. et al. Fatores que influenciam o compartilhamento da informação e do conhecimento. Perspectivas em Ciência e Informação, Belo Horizonte,v. 14, n. 1, p.117-191, 2009.

BABBIE, Earl. Métodos de pesquisa de Survey. Tradução de Guilherme Cezarino. Belo Horizonte: UFMG, 1999. Título original: Survey research methods.

BLUMER, Herbert. Symbolic interacionism: perspective and method. USA: University of California, 1986.

BOWLBY, John. Attachment and loss: attachment. London: Basic Books, 1969.

BRASIL. Congresso Nacional. Lei n. 10.861 de 14 de abril de 2004. Institui o Sistema Nacional de Avaliação da Educação Superior - SINAES e dá outras providências. Diário Oficial [da] República Federativa do Brasil, Poder Executivo, Brasília, DF, 15 abr. 2004. Seção 1. p. 3. Disponível em: <http://www.planalto.gov.br/ccivil_03/_ato2004-2006/2004/lei/110.861.htm>. Acesso em: 28 dez. 2012.

BRASIL. Ministério da Educação. Portaria n. 300 de 30 de janeiro de 2006. Aprova, em extrato, o instrumento de avaliação externa das Instituições de Educação Superior do Sistema Nacional de Avaliação da Educação Superior - SINAES. Diário Oficial [da] República Federativa do Brasil, Poder Executivo, Brasília, DF, 31 jan. 2006. Seção 1. p. 5. Disponível em:

<http://meclegis.mec.gov.br/documento/view/id/75>. Acesso em: 28 dez. 2012. 
CAPURRO, R.; HJØRLAND, B. O conceito de informação. Perspectivas em Ciência da Informação, Belo Horizonte, v.12, n.1, 2007. Disponível em:

<http://portaldeperiodicos.eci.ufmg.br/index.php/pci/article/view/54>. Acesso em: 19 jul. 2013.

CHOO, C. W. A organização do conhecimento: como as organizações usam a informação para criar significado, construir conhecimento e tomar decisões. São Paulo: Senac, 2006.

COELHO, Maria do Socorro Costa. Opinião: Egresso e Universidade. Beira do Rio - Jornal da Universidade Federal do Pará, Belém, v. 24, n. 72, maio 2009.

Disponível em: <http://www.jornalbeiradorio.ufpa.br/novo/index.php/2009/3edicao-72/27-egresso-e-universidade>. Acesso em: 20 dez. 2012.

DATE, C. J. Introdução a sistemas de banco de dados. Daniel Vieira (Trad.). Rio de Janeiro: Elsevier, 2003.

DUMONT, Lígia Maria Moreira. O não-usuário de serviços de informação, este ilustre desconhecido. In: CONGRESSO BRASILEIRO DE BIBLIOTECONOMIA E DOCUMENTAÇÃO, 17, 1994, Belo Horizonte. Anais... Belo Horizonte:

Associação dos Bibliotecários de Minas Gerais, 1994.

FARIA, Carla Maria G. M. Vinculação e desenvolvimento epistemológico em jovens adultos. 2008. $282 \mathrm{f}$. Tese (Doutorado em Psicologia) - Universidade do Minho, Braga, 2008.

FIGUEIREDO, Nice Menezes de. Estudos de uso e usuários da informação. Brasília: IBICT, 1994.

HOLLIS, James. O projeto Éden, a busca do outro mágico. São Paulo: Paulus, 2002.

LE COADIC, Yves-François. A ciência da informação. Tradução de Maria Yêda F. S. de Filgueiras Gomes. 2. ed. Brasília: Briquet de Lemos, 2004. 124 p. Título original: La Science de L'information.

LOUSADA, Ana Cristina Zenha; MARTINS, Gilberto de Andrade. Egressos como fonte de informação à gestão dos cursos de Ciências Contábeis. Revista

Contabilidade \& Finanças, São Paulo, n. 37, p. 73-84, jan./abr. 2005. Disponível em: <http://www.revistas.usp.br/rcf/article/view/34151>. Acesso em: 16 mar. 2015.

MAEL, Fred; ASHFORTH, Blake E. Alumni and their alma mater: A partial test of the reformulated model of organizational identification. Journal of Organizational Behavior, Oxford, v. 13, p. 103-123, 1992. Disponível em: < https://www.researchgate.net/publication/229700250_Alumni_and_Their_Alma_Ma ter_A_Partial_Test_of the Reformulated_Model_of_Organizational_Identification> . Acesso em: 24 abr. 2013. 
McDEARMON, J. Travis. Hail to Thee, Our Alma Mater: Alumni Role Identity and the Relationship to Institutional Support Behaviors. Research in Higher

Education, Athens, v. 54, p. 283-302, 2012. Disponível em:

<http://link.springer.com/article/10.1007/s11162-012-9271-6>. Acesso em: 13 maio 2013.

MEIRA, Maria Dyrce Dias; KURCGANT, Paulina. Avaliação de curso de graduação segundo egressos. Revista da Escola de Enfermagem da USP, São Paulo, v. 43, n. 2, p. 481-485, 2009. Disponível em:<http://www.scielo.br/pdf/reeusp/v43n2/a31v43n2.pdf> Acesso em: 19 jan. 2015 .

NONAKA, Ikujiro; TAKEUCHI, Hirotaka. Criação de conhecimento na empresa: como as empresas japonesas geram a dinâmica da inovação. 3. ed. Rio de Janeiro: Campus, 1997.

PEARSON, Jerold. Comprehensive research on alumni relationships: Four years of market research at Stanford University. New Directions for Institutional Research, Burlington, v. 101, p. 5-21, 1999. Disponível em: <http://onlinelibrary.wiley.com/doi/10.1002/ir.10101/abstract>. Acesso em: 03 jan. 2014.

QUEIROZ, Tatiana Pereira. O bom filho a casa sempre torna: análise do relacionamento entre a Universidade Federal de Minas Gerais e seus egressos por meio da informação. 2014. Dissertação (Mestrado em Ciência da Informação) Universidade Federal de Minas Gerais, Belo Horizonte, 2014. Disponível em: <http://www.bibliotecadigital.ufmg.br/dspace/bitstream/handle/1843/BUOS9PRKWC/disserta_o_tatiana_pereira_queiroz__02_09_14__vers_o_final.pdf?se quence $=1>$. Acesso em: 10 mar. 2015.

SAMUELS, Andrew. A política no divã. São Paulo: Summus, 2002.

UNIVERSIDADE FEDERAL DE MINAS GERAIS. Faculdade de Filosofia e Ciências Humanas. Núcleo de Avaliação de Políticas Sociais. Belo Horizonte, 2007. Disponível em: 〈https://www.ufmg.br/egressos/pesquisa.htm>. Acesso em: 30 jun. 2015.

WILSON, Thomas Daniel. Information needs and uses: fifty years of progress? In:VICKERY, Brian Campbell(Org.). Fifty years of information progress: a journal of documentation review. London: Aslib, 1994. p. 15-51 


\title{
Dimensions of the relationship between the university and its alumni through information: the case of the Federal University of Minas Gerais (Universidade Federal de Minas Gerais)
}

\begin{abstract}
The aim of this article is to present the results of a study to identify mechanisms of relationship between a Higher Education institution and its alumni. The authors investigated how information systems can be improved with the objective of facilitating data management of graduates of educational institutions in order to improve the connection between them. The environment analyzed was the alumni program of the Federal University of Minas Gerais (Universidade Federal de Minas Gerais), Sempre UFMG, and the units of analysis are the graduates who had their e-mail address registered at the university. An electronic survey was carried out with 1.445 respondents. The study was based on theoretical constructs of social and organizational identification; psychosocial role; attachment and information needs. Results point to the need of fostering the relationship between the institution and the student from the very beginning until after they graduate.
\end{abstract}

Keywords: Users of information. Potential users of information. Information systems. Alumni relationship. Organizational identification profile. Attachment. Decision-making.

Recebido em: 12/05/2015

Aceito em: 06/07/2015

${ }^{1}$ Documento eletrônico não paginado.

2 UNIVERSIDADE FEDERAL DE MINAS GERAIS. Departamento de Registro e Controle Acadêmico. Relatório interno de ex-alunos. Belo Horizonte: UFMG, 2015. Não publicado.

${ }^{3}$ TOLMAN, E. C. Identification and the post-war world, Journal of Abnormal and Social Psychology, 38, $p$. 141-148, 1943.

${ }^{4}$ STRYKER, S. Symbolic interactionism: A social structural version. Caldwell, New Jersey: The Blackburn Press, 2002.

${ }^{5}$ STRYKER, S. Symbolic interactionism: A social structural version. Caldwell, New Jersey: The Blackburn Press, 2002.

${ }^{6}$ CAVANHAUG, J. Adult development and aging. California: Cole Publishing Company, 2005.

${ }^{7}$ SCHAIE, W.; WILLIS, S. Adult development and aging. London: Prentice Hall, 2002.

8 DOHERTY, N.; FEENEY, J. The composition of attachment networks throughout the adult years. Personal Relationships, v. 11, p. 469-488, 2004.

${ }^{9}$ CRONIN, B. Assessing user needs. Aslib Proceedings, Londres, v. 33, n. 2, p. 37-47, fev. 1981. 
${ }^{10}$ LANCASTER, F. W. Information retrieval systems: characteristics, testing and evaluation. 2. ed. New York: J. Wiley, 1979.

${ }^{11}$ WILSON, T. D. Information needs and uses: fifty years of progress? In: Vickery, B.C., ed. Fifty years of information progress: a Journal of Documentation review. London: Aslib, 1994, 15-51. 